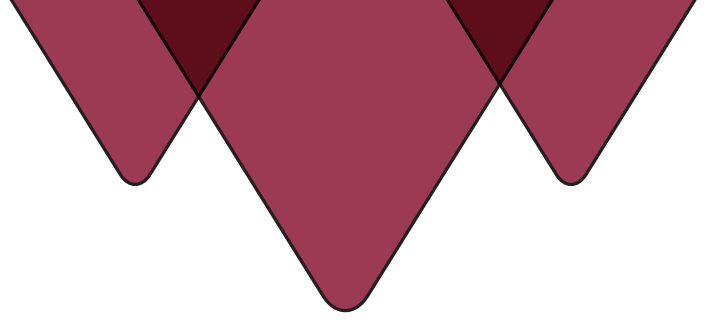

\title{
Book Review: Collaborations for Student Success: How Librarians and Student Affairs Work Together to Enrich Learning
}

Long, Dallas. (2019). Collaborations for Student Success: How Librarians and Student Affairs

Work Together to Enrich Learning. Lanham: Rowman \& Littlefield, I9Ipp, \$36.0o USD.

\section{Amanda Hahn}

Liberty University

Keywords: academic librarianship · collaborations · partnerships · student affairs

Many academic libraries would affirm the value of inter-campus collaboration as a way to increase the library's presence on campus, but how do they decide whom to partner with and how? While some partnerships may be more naturally obvious opportunities for collaboration, such as coordinating with academic departments or a campus writing centre, other partnerships may be less apparent and require more effort and tenacity in order to become effective. In this book, author Dallas Long examines one such potential partnership, that of the library and student affairs.

Stemming, in part, from the author's own unique experience working as a librarian within a college residence hall, the book explores how librarians and student affairs professionals view both their own work and role on campus, as well as their perceptions of the work and values of one another. The book is centred upon original research by the author, initially conducted for his dissertation. Long has published and presented extensively on various topics related to academic librarianship, including work that further examines the role of student affairs professionals on campus.

This title provides a helpful overview discussing both the student affairs professional and the academic librarian, explaining how their responsibilities have evolved over time and the values that shape their work today. While both groups described their work as having an impact on student learning, they often spoke about student learning in different ways, showing that the groups were missing a shared vocabulary. As the author notes throughout the book, one of the primary barriers 
preventing these two groups of professionals from collaborating with one another is a fundamental lack of understanding in what the other does.

The research presented within this book is helpful, but it is worth noting that the sample size was limited. Long conducted a series of focus groups at five different institutions of higher education. There were two focus groups at each institution, one with librarians and one with student affairs professionals. With only 55 total participants, this research provides some valuable initial insights, but is too small of a sample to form many substantial conclusions. Long acknowledges the limitations of the research and recognizes that there are opportunities for further study into experiences of these two groups at other institutions.

Many of the librarians who participated in the author's focus groups seemed unfamiliar with which campus services were a part of student affairs, which is unsurprising when one considers the multiple offices student affairs can encompass, including (but not limited to) academic advising, admissions, campus ministries, career services, Greek affairs, health services, housing and residential life, student conduct, leadership programs, multicultural student services, new student programs, recreation and fitness, and student activities. Further research may benefit from looking at specific student affairs services, rather than student affairs as a whole.

From their own viewpoint, student affairs professionals expressed that librarians appeared to be confined to the library and were not interested in expanding their reach. This lack of understanding, when accompanied with a disparity in identified values, makes it difficult for these two groups to engage in meaningful collaboration. The most valuable part of this book may be that it gives readers a foundational understanding of these two professions, and particularly that it gives its intended audience of librarians a solid introduction into the values and approaches that shape the student affairs field, making it a vital starting point for those librarians who desire to seek out opportunities for collaboration at their own institutions.

While the book draws necessary attention to the differences between these two groups, it would be incorrect to conclude that they have no similarities. Long does make note of several areas where the professions and values overlap and these areas merit further study and exploration. Both fields are service-oriented and both librarians and student affairs professionals are motivated within their work to remove barriers that impact a student's opportunity to pursue education. These two professions also both promote critical thinking and lifelong learning. It is upon these commonalities that librarians and student affairs professionals might begin to collaborate with one another to enrich student learning and development. 
Long's conclusion could be described as bleak, stating "I now believe that librarians and student affairs professionals dwell in different worlds and are more dissimilar than I had previously thought. Where I was idealistic in my belief that librarians and student affairs professionals could and should collaborate together to improve student learning and success at the beginning of my book, I am now skeptical that they are appropriate prospective collaborators" (I68). While these conclusions are a fair reflection of the focus group findings, it leaves readers without clear recommendations for future practice.

The main critique of this book, in my opinion, is that the title does not aptly describe or reflect the book's content. Long's research shows little to no evidence of the professions working together, which is antithetical to the book's subtitle: How Librarians and Student Affairs Work Together to Enrich Learning. Readers should be aware that this is not a book that provides specific examples of collaborative events or services that bring these two professions together, nor does it offer much in the way of best practices for building relationships with other campus departments. It is, however, a valuable foundational work in understanding the intersections and differences between librarians and student affairs professionals. A familiarity with these differences will be key to those desiring collaborative partnerships so they can proceed with an awareness of the probable challenges and pitfalls they will encounter along the way. 